\title{
HACIA EL TRADUCTOR DE LA ZUCCA DEL DONI EN SPAÑOL
}

\author{
DANIELA CAPRA \\ Università di Modena e Reggio Emilia
}

En el mes de octubre de 1551, a los pocos meses de publicarse en Venecia la primera parte de la Zucca de Anton Francesco Doni, sale de los tórculos del mismo impresor, Francesco Marcolini, La Zucca del Doni en Spañol; la obra se compone de anécdotas, facecias y breves historias que terminan con uno o más proverbios a los cuales el autor añade a menudo un comentario o una reflexión, que a su vez puede finalizar con otro proverbio más. El material va repartido en tres capítulos llamados Cicalamentos, Baias y Chácharas, cuyo contenido es similar, ya que comparten la misma estructura y tamaño ${ }^{1}$; cierra

\footnotetext{
${ }^{1}$ De «obra-contenedor» habla E. Pierazzo, la editora moderna del texto italiano, del que citamos, en su «Introduzione» a Anton Francesco Doni. Le novelle. La Zucca, Salerno Editrice, Roma, 2003, ya que la serie de anécdotas que estructura el texto es solo uno de los tipos narrativos, al cual se suman otros muy dispares que hacen de la Zucca una obra difícil de definir y describir. Es esta la razón principal de su olvido durante siglos, a la que hay que añadir los juicios morales sobre la desordenada vida del autor, que ha motivado tanto la falta de reediciones ya a partir de la época barroca, con su reacción a las tendencias más extravagantes del Renacimiento, como unos comentarios muy duros por parte de la crítica, que condenaba vida y obra de este autor; en Italia B. Croce, tan influyente en la historia del pensamiento literario, en Poeti e scrittori del pieno e tardo Rinascimento, Laterza, Bari, 1958, habla de una «vita nulla, deserta d'ogni fine» (pág. 273) y en España M. Menéndez Pelayo no es menos duro, ya que le tilda de «libelista cínico», describiéndolo como un «escritor de los que hoy llamaríamos excéntricos o humoristas y que entonces se llamaban heteróclitos o extravagantes, lleno de raras fantasías, tan desordenado en sus escritos como en su vida, improvisador perpetuo»: cf. Orígenes de la novela, III, IX, pág. 32, [también en línea] http://www.larramendi.es/menendezpelayo [consulta 06/08/2015].
} 
la obra una cuarta sección, que contiene cartas enviadas o recibidas por Doni y titulada Post scripta. Las tres secciones narrativas - con sus moralejas en forma de proverbio que sirven como conclusión de cada anécdota o donairehan de leerse horacianamente como una mezcla de deleite y amonestación, esta no siempre (o no solamente) en sentido moral, sino también en cuanto aplicación del sentido común al vivir cotidiano, aunque a veces estos textos se resuelven en un puro juego de ingenio, revelando la más auténtica naturaleza del espíritu doniano.

El nombre del traductor no aparece en la dedicatoria ni en otros paratextos y su identidad nos es hoy desconocida. A mediados del Quinientos, en Venecia, el interés hacia los libros españoles era muy amplio y eran muchas las ediciones originales y las traducciones que se iban llevando a cabo, así como numerosos eran los protagonistas de dichas actividades, ya fuesen editores, libreros, autores o colaboradores editoriales y traductores ${ }^{2}$; en este marco, adquiere particular relevancia la cuestión, si no de la identidad, al menos de la personalidad del traductor de la obra. En el presente trabajo nos proponemos, pues, tomando como punto de partida la dedicatoria que antepone a su versión de la obra doniana el traductor, intentar acercarnos a un posible perfil suyo, a través de una reflexión acerca de diferentes cuestiones textuales y extratextuales.

El encabezamiento de dicha dedicatoria reza: Al Illustre Señor Juan Battista de Diuicij Abbad de Bibiena, y de San Iuan in Venere. El destinatario de la traducción es, pues, Giovan Battista Dovizi, personaje de segunda o incluso tercera fila, del que muy poco se sabe; algo más conocemos de otros miembros de su familia: en efecto Giovan Battista Dovizi fue sobrino del famoso cardenal Bernardo Dovizi (1470-1520), llamado Bibbiena por el lugar donde nació y conocido hoy por ser el autor de la Calandria, una exitosa comedia que se representó por primera vez en 1513 en Urbino y se imprimió en numerosas ocasiones en diferentes ciudades italianas, aunque solo a partir de 1521, es decir, después de la muerte de su autor3. La brillante carrera del cardenal Bibbiena,

\footnotetext{
${ }^{2}$ No me detendré en esta cuestión: la bibliografía sobre este sector de estudios es enorme y es imposible dar cuenta de ella aquí; por tanto, me limitaré a recordar que un catálogo exhaustivo de textos en castellano editados en Venecia en el siglo XVI se puede leer en A. Bognolo, «El libro español en Venecia en el siglo XVI», en M. L. Cerrón Puga (ed.), Rumbos del hispanismo en el umbral del Cincuentenario de la AIH, III, Bagatto Libri, Roma, 2012, págs. 243-258; en cuanto a los protagonistas de esta difusión de la cultura española, no hay que olvidar el papel de los mismos representantes de la Corona imperial, como el cónsul y algunos secretarios de la embajada, los cuales directa o indirectamente han contribuido a dicha propagación: el tema se aborda en parte en D. Capra, «Il libro spagnolo in Italia nel Cinquecento come veicolo di mediazione culturale», en M. Bondi, G. Buonanno y C. Giacobazzi (eds.), Appartenenze multiple. Prospettive interdisciplinari su immigrazione, identità e dialogo interculturale, Officina, Roma, 2011, págs. 95-106.

${ }^{3}$ La princeps llevaba por título Commedia elegantissima in prosa nuouamente composta per messer Bernardo da Bibiena. Intitulata Calandria y se publicó en Siena; a partir de la siguiente edición (Venecia, hacia 1522) aparece como Calandra: para el listado completo se puede consultar ICCU. Edit16 [en línea] http://edit16.iccu.sbn.it/web_iccu/ihome.htm [consulta 26/02/2015].
} 
sin embargo, no se debía a su talento de autor teatral; empezó con su llegada a Florencia en pos del hermano mayor Piero, notario, quien desde la aldea de la comarca de Arezzo donde ambos habían nacido se instaló en Florencia en 1480, y llegó a ser canciller por voluntad de Lorenzo il Magnifico ${ }^{4}$. El joven Bernardo en cambio se hizo muy amigo de uno de los hijos del mismo Lorenzo de' Medici, Giovanni (1475-1521), que en aquel momento, pese a su temprana edad, ya era cardenal y más tarde sería papa (desde 1513) con el nombre de León $\mathrm{X}^{5}$. El destino de Bernardo está fraguado y en Roma llegará a ser un poderoso cardenal protegido por el papa.

A la ciudad eterna llegan también otros miembros de la familia en 1494, cuando, tras la muerte de Lorenzo (acontecida en 1492) y con el poder en manos del hijo Piero (1472-1503) la situación política deja de serles favorable y son proscritos de Florencia. Entre los exiliados está también otro hermano, el tercero, del futuro cardenal, que se llama Giovan Battista y es el padre del destinatario de la traducción; como su hermano Piero, era notario y en Florencia estaba al servicio de los Medici, Giovan Battista con el cargo de capitán de Palacio (capitano di Palazzo), cargo que le había asegurado un discreto nivel socioeconómico. De sus siete hijos, cuatro hembras y tres varones, el más conocido es Angelo, el más joven, porque se crió con el tío y desempeñó los cargos de secretario suyo y de protonotario apostólico ${ }^{6}$. A la muerte del cardenal heredó, entre otros bienes, los beneficios de la abadía de San Giovanni in Venere, en los Abruzos, que por alguna razón pasó luego al hermano Giovan Battista, nuestro destinatario. Es posible que esa transferencia de cargos tuviera lugar muy pronto, ya que en enero de 1523 y hasta el mes de septiembre del año siguiente| Angelo Dovizi encargó a Francesco Berni el cuidado de la abadía nombrándolo subvicario; el rústico ambiente de los Abruzos, empero, no le gustó al Berni, quien prefirió volverse a Roma, perdiendo sin embargo en el mismo momento el apoyo del Dovizi

${ }^{4}$ Véase Istituto dell'Enciclopedia Italiana. Dizionario Biografico degli Italiani (DBI) [en línea] <http://www.treccani.it/biografie/> [consulta 02/02/2015].

5 Parece un hecho comprobado la homosexualidad de Giovanni de' Medici, y la gran amistad con el Bibbiena induce a pensar que compartían algo más que el mero interés por la religión.

${ }^{6}$ Otra razón por la que es conocido es que tuvo a su servicio al poeta Francesco Berni (1497-1536), que había sido secretario de su tío el cardenal hasta 1520; los dos Dovizi, tío y sobrino, ligados por un lejano parentesco con Berni, mantuvieron con este una relación no siempre serena durante años, pero luego el escandaloso comportamiento del poeta causó la ruptura definitiva.

${ }^{7}$ Estos datos se pueden rastrear de la lectura de la obra berniana. En efecto, en algunos poemas del Berni (Rime, ed. de D. Romei, Mursia, Milán, 1985), quedan registrados comentarios e impresiones sobre diferentes episodios que los ven involucrados; entre ellos hay un soneto que da cuenta de su estancia en la abadía de San Juan, de la que Dovizi tenía el priorato, heredado de su tío. El elocuente y sabroso poema del Berni dice así: «Amor, io te ne incaco,/ se tu non mi sai far altri favori,/ perch'io ti servo, che tenermi fuori./ Può far Domenedio che tu consenti/ che una tua cosa sia/ mandata nell'Abruzzo a far quitanze/ e diventar fattor d'una badia/ in mezzo a certe genti/ che son nemiche delle buone usanze?/ Or s'a queste speranze/ 
A causa de la epidemia de peste que estalló en Roma en 1522 y suponemos que también por los cambios que siguieron a la muerte del Papa, los Dovizi se fueron volviendo a Toscana; en particular, Angelo consiguió instalarse en Florencia, donde más adelante (a partir de 1544) aparece como secretario del duque Cosimo de' Medici; sus dos hermanos, Antonio y Giovan Battista, al parecer - algunas cartas conservadas lo atestiguan $(D B I)$ - estaban en Bibbiena: este último con el cargo de abad de las dos abadías recordadas por el traductor.

Otra noticia acerca del destinatario de la traducción nos viene de Alfonso de Ulloa, quien en su Vita del valorosissimo e gran capitano don Ferrante Gonzaga (1563) cuenta que Giovan Battista Dovizi fue hecho prisionero de los turcos en 1538 y se libró gracias al pago de un rescate:

Barbarossa [...] si spinse innanzi alla retroguardia de' Venetiani, la quale, disserrando molte volte cannonate, fra la oscurità del fumo et il cominciare della notte, si salvò seguendo gli altri verso Corfù, restandone solo due prese da' nimici, delle quali erano sovracomiti $\mathrm{M}$. Francesco Mocenigo gentilhuomo Venetiano, fratello di M. Luigi, chiarissimo e prestantissimo Senatore che hoggi vive [...]. E l'altro sovracomito fu Monsignor Giovan Battista Bibbiena, gentilhuomo ancora egli honorato e virtuosissimo e parimente degno di ogni laude: il quale era andato a servire il Papa in quella impresa e si liberò poi pagandone una grossa taglia in Constantinopoli (100v-101r).

El traductor de la Zucca, pues, conoce a este abad, que en el momento de redactarse la dedicatoria tenía unos 50 años; es más, le dedica su traducción porque tiene una antigua deuda con él y no sabe cómo pagársela, ya que sus escasos medios no le permiten muchas alternativas: eso leemos en la dedicatoria, donde por otra parte no se ofrecen detalles biográficos que nos permitan llegar a la identidad del traductor, ni a la razón y la época de su trato:

[...] es muy nesçesario [...] buscar tiempo, saçón, y lugar para regraciar con obras, o palabras, a los que nos han hecho algun beneficio. Y si con obras no podemos, por no tener aparejo ni posibilidad, alomenos mostrarles con buenas palabras el deseo que tenemos de cumplir con obras. Siendo yo, pues, deudor por tantas partes a V. M. no he querido ser de los que pagan luego $\longrightarrow$ o por mejor dezir, no he podido serloni tampoco de los que tardan en pagar, por no ser tachado de hombre desconocido ${ }^{8}$.

sta tutto il resto de' tuoi servitori/ per nostra Donna, Amor, tu me snamori» (n. 21); véase también el soneto $20 \mathrm{~B}$, que empieza dirigiéndose a Angelo con las palabras «Divizi mio» para llegar a decirle «ma pur Roma ho scolpita in mezzo il cuore» (v. 12), mientras se encuentra en su exilio de los Abruzos «fra sterpi e sassi e villan rozzi e fieri,/ pulci, pidocchi e cimici a furore» (vv. 9-10); en otros poemas critica a Antonio Dovizi.

${ }^{8} \mathrm{La}$ acepción de «desconocido» como «desagradecido» no era rara y coexistía con la actual. El CORDE (http://www.rae.es) presenta un buen número de ejemplos de los diversos significados de esta palabra, que muestran cómo el valor de «desagradecido» no ha sido nunca preponderante 
El pago de lo debido es también un tópico de las dedicatorias, pero por lo general se recurre a él como expediente cuando todo el mundo reconoce el prestigio del destinatario: admitiendo su obligación el autor demuestra su deferencia hacia él; sin embargo, el abad no era un personaje muy conocido: se trata, en cualquier caso, de una demostración de respeto hacia el destinatario, para una pretendida deuda de probable naturaleza simbólica, no económica, que no se podía pagar con dinero; el poder de la palabra funciona pues como instrumento apto para este propósito?.

En el encargo de esta traducción nuestro anónimo personaje ve por tanto la oportunidad de brindarle un homenaje al Dovizi, librándose de su supuesta deuda. Que la traducción fuera un encargo y no una iniciativa personal se infiere claramente de su relato de cómo se fraguó el proyecto de la traducción; en la larga dedicatoria, justo a continuación de las consideraciones arriba citadas, dice:

desde el punto de vista cuantitativo y va perdiendo terreno a lo largo del siglo XVII, siendo raro en el siguiente. Todas las citas del texto español de la Zucca provienen de nuestra edición crítica Antonfrancesco Doni. La Zucca en Spañol (Academia University Press, Turín, 2015), cuyo texto se ha modernizado solo en cuanto a la puntuación, la inserción de acentos tónicos según las reglas actuales y la transcripción de unos pocos grafemas (actualización de $u$ y $v, s$ alta).

${ }_{9}^{9}$ Compárense las palabras del traductor con el siguiente texto, escrito por A. de Guevara: «Consideradas las mercedes que yo he rescebido de vuestra señoría, [...] si por algún descuido yo fuese en todo ello ingrato y desconocido, justamente merescía ser con la ley de Dracón [...] castigado. [...] Podráme vuestra señoría argüir que sé poco, puedo poco, tengo poco, valgo poco; mas nunca quiera Dios que me acuse de ser ingrato, porque si las mercedes que he resçebido de mis señores y amigos no las puedo pagar, a lo menos no las dexo de conosçer y, cuando puedo, reconosçer» (Libro primero de las epístolas familiares, I, «Letra para don Fadrique de Portugal, Arzobispo de Zaragoza y viso rey de Cataluña»; cito de la edición de Madrid, 1595, pág. 323, en línea: https://books.google.es/books [consulta: 15/02/2015]). La inmensa popularidad del obispo de Mondoñedo en Italia y su fortuna editorial en lengua italiana dejan suponer que el traductor había leído en uno u otro idioma estas líneas, cuya traducción italiana, firmada por D. de Gaztelu, salió en Venecia en 1545; véanse estas mismas líneas tal como las tradujo Gaztelu, que insiste en algunos aspectos, con amplificaciones: «Considerate i doni et favori che io ho da vostra Reverendissima Signoria, [...] se per inavertenza io fusse stato in tutto o in parte sconoscente, ingrato, secondo le leggi di Dracone meritarei essere gravemente punito. Vostra Signoria potrà arguire ch'io so poco, posso poco, et tengo poco, ma Iddio non voglia mai che niuno mi accusi d'ingratitudine, impero che se le mercedi e doni che da li miei signori et amici io ricevo non posso pagargliele, almeno le riconosco bene col cuore, et quando posso, anchora con le opere le recompenso») (cito el Libro primo delle lettere de la edición de Giolito de 1551, en línea: https://books.google.it/books [consulta 16/03/2015]; el pasaje está en la pág. 209v); repárese en que la idea de conocer y reconocer se refuerza en italiano con los verbos riconoscere (bene) y ricompensare. También en la dedicatoria del mismo Libro delle lettere hay una idea que coincide con una de la dedicatoria de la Zucca en español y no faltan puntos de contacto entre las actividades del tudelano Gaztelu y una posible autoría de esta traducción, pero los débiles indicios no permiten llegar a conclusiones con viso de probabilidad; los textos a los que se dedicaba este hombre, que en Venecia era secretario de la Embajada española, eran más graves, pero estos mismos hechos podrían haber sido buenas razones para que, aun siendo el autor, no hubiese querido firmar esta traducción de una obra demasiado liviana respecto a sus ocupaciones e inclinaciones habituales. 
[...] susçedió que estando con el Doni (hombre, como Vuestra Merced sabe, agudo) venimos a hablar de la Zucca, que él no ha muchos días hizo estampar. Roguéle que me embiase una por que no havía provado calabaças este año; él lo hizo como amigo, agradóme la materia e argumento del libro [...] encarecísele tanto al Señor Conde Fortunato de Martiniengo, que él, como deseoso de saber nuestro lenguaje, allende de ser tan aficionado a la nación Española, me rogó con gran instancia le tradujese, poniéndome delante la utilidad y provecho que de allí redundaría a muchos que caresçen de la lengua Italiana. Conoscida su voluntad (aunque querría más escrevir de mio si supiese que traduzirlo de otros) le otorgué lo que me pidió.

A pesar de estas palabras, se podría incluso plantear la posibilidad de que el proyecto no naciera exclusivamente por petición ajena debida al azar del encuentro, sino que fuera el mismo Doni quien tuviese la ambición de ver su Zucca traducida y hubiese propuesto la tarea a un español amigo suyo ${ }^{10}$, y gracias a la liberalidad del conde Martinengo, amigo de Doni y de muchos escritores y artistas que por aquel entonces vivían en la Serenissima, el proyecto se pudiera llevar a cabo. No olvidemos que el mismo Doni traduce o por decir mejor adapta el Exemplario contra los engaños y peligros del mundo — versión a su vez derivada de un texto en latín emparentado con el Sendebar ${ }^{11}$ _ que con el título de La moral 'filosophia del Doni, tratta da gli antichi scrittori publica con su impresor de confianza en Venecia, Francesco Marcolini, en $1552^{12}$. Es incluso posible que el traductor español haya asesorado a Doni en su lectura del texto del Exemplario. Sea ello como quiera, es importante apuntar que el traductor no tuvo un papel de primer plano en la decisión de traducir y dar a la imprenta el texto, lo cual nos induce a descartar personajes preeminentes en la sociedad o en el mundillo cultural o editorial veneciano y lleva a sospechar que se trate más bien de una persona que en su cotidianidad se dedicaba a otro tipo de tareas.

Por otra parte, la conexión con un destinatario toscano nos induce a tomar en consideración la hipótesis de la existencia de un trato precedente del traductor con un ambiente que podría ser el mismo que Doni conocía antes de instalarse

\footnotetext{
${ }^{10}$ Así lo califica en una carta Doni: véase el texto completo en E. Pierazzo, op. cit., pág. 664.

${ }^{11}$ La compleja historia de esos cuentos indios está trazada por M. J. Lacarra, «El Exemplario contra los engaños y peligros del mundo: las transformaciones del Calila en Occidente», en M. Haro Cortés (dir.), Exemplario contra los engaños y peligros del mundo: estudio y edición, Universidad de València, 2007, págs. 15-41. Una versión italiana precedente a la preparada por el Doni fue cuidada por Agnolo Firenzuola y se imprimió póstumamente en Florencia en 1548 con el título de La prima veste de' discorsi degli animali.

${ }^{12}$ Es un momento de interés hacia lo español por parte de Marcolini, que también publica un texto de Luis de Ávila y Zúñiga (1500-1564), El primer comentario del muy illustre senor don Luys de Auila y Cuniga en la guerra de Alemania (1552); esta obra se publicó por primera vez en 1548, tanto en español como en italiano, y se editó al año siguiente en italiano con un título algo diferente; en estas primeras ediciones no aparece el nombre del editor, pero sí del que promovió las impresiones, el cónsul español en Venecia Tomás de Zornoza (cf. Edit16, ed. cit.).
} 
en Venecia; incluso podríamos pensar que el anónimo traductor fuese un religioso, no solo por ser el destinatario de la traducción un abad, sino también por otras razones, entre las cuales contamos algún cambio que introduce en la traducción, como el resistirse a hablar mal de la religión o los conocimientos que demuestra de los textos sagrados.

En cuanto a lo primero, llama la atención, en el contexto general de una traducción bien hecha, la discrepancia evidente y voluntaria entre el italiano y su versión española de la siguiente oración:

Quanti ci sono oggi che non fanno profession d'altro che di dir bugie? Quanti sono adulatori e quanti mentiscono di parola in parola che esce loro di bocca? Vadisi nelle corti, cerchisi le religioni e riguardinsi le famiglie e si comprenderà quanto il nimico nostro vi sia per la parte sua (pág. 109).

¿Quántos se hallan hoy en día que de ninguna otra cosa hacen profesión sino de mentir y lisonjear? ¿Y quántos son los que mienten en todas las palabras que echan por boca? Muy claro se vee esto en las Cortes delos Príncipes, pues en las Religiones no. Váyanse a las casas y familias donde veerán cuan de veras nuestro enemigo les haze espaldas (Baia II).

Es evidente la voluntad del traductor de alejarse del original e incluso negar polémicamente una insinuación malévola del Doni; el traductor casi con fastidio contradice el texto original entrando en el terreno de una discusión, en lugar de limitarse a omitir el sintagma.

En cuanto a lo segundo, o sea los conocimientos que demuestra de los textos sagrados, entre los lugares que podemos aducir, quizás el más evidente sea el que se encuentra al final de una anécdota en que Doni habla de los lisonjeros y cita la oración «este pueblo con la lengua me honra, pero no con el corazón», atribuyéndola a David; el traductor corrige la atribución errada y la devuelve a Isaías, como corresponde. A la luz de todo esto, es bastante probable que el anónimo traductor haya tenido una educación religiosa y además no tolerara las críticas genéricas como la que hemos citado arriba ${ }^{13}$.

Incluso el lenguaje empleado y la corrección formal de su prosa parecen apuntar hacia una formación en el seno de la Iglesia: a lo largo de la traducción se nota, por ejemplo, una tendencia a regularizar la sintaxis a veces algo caprichosa del texto original y a formar oraciones más claras, con una atención al texto típicamente 'de escuela', no espontánea; compárense, a manera de ejemplo, el siguiente texto original y su traducción:

${ }^{13}$ Otros lugares del texto doniano donde se alude negativamente a algún personaje de la Iglesia se encuentran traducidos sin cambios, pero se trata a todas luces de casos diferentes; otro ejemplo de su conocimiento de los textos sagrados, en cambio, es la omisión del sustantivo «profeta» detrás del nombre Amos (Baia primera), seguramente por considerar superflua la información que en el texto original se encuentra. 
Alcuni ingegneri facendo un lor cassone da cavar le navi sommerse e trarle dal fondo facendole venir sopra acqua, un giorno il signor Ercole Bentivoglio e io andammo a veder questo artificio. - Che ve ne pardiss'egli [...] (pág. 121).

Algunos ingenieros, haziendo ciertas caxas para sacar las naves que se hundían del profondo del mar y hazerlas venir sobre el agua, hizieron un día la prueva. Hallándome yo allí con el Señor Hércules Bentivollo, él me dixo: [...] (Baia IX).

De la misma manera, en otros pasajes del texto introduce conectores $u$ otros elementos oracionales para explicitar la progresión lógica del texto y dar mayor cohesión a la oración, como se puede comprobar en los siguientes fragmentos: «voglio ben mostrarvi che certi dei hanno le corna, come è Bacco [...]»y «pero con todo esso, quiero mostrar que ciertos Dioses traen cuernos, como Bacco [...]» (Baia última), donde la inserción de la locución conjuntiva con valor adversativo «pero con todo esso» desempeña esta doble función y añade coherencia al párrafo donde se inserta; lo mismo en:

Ancora si osserva questa nimicizia fra gl'uomini trasformati in cervi et gl'uomini ragionevoli, per la sentenza di Giove. E che sia il vero, come si prende un cervio alla caccia, subito s'appiccono le corna sopra la porta, come cosa che stia per trofeo honorato (pág. 150).

También se guarda esta enemistad entre los hombres trasformados en ciervos y los hombres razionales conforme ala sentencia de Júppiter. Y que sea esta la verdad, bien se paresçe, por que quando caçan algún ciervo, luego plantan los cuernos ala puerta, como señal de un triunfo muy honrrado (Baia última).

Añadiendo bien se parece y la cojunción porque se completa el comienzo de la oración «Y que sea esta la verdad», que en italiano queda suspendido.

En cuanto al léxico, se evitan las manifestaciones disfémicas de Doni y las palabras ofensivas, y se opta por la moderación, como se desprende de los casos siguientes:

Se questo bestiuolo avesse saputo il proverbio che s'usa dire, forsi che sarebbe andato più ritenuto nello scacazzare i fogli per dargli alle stampe (pág. 61).

Si este nesçio trujera ala memoria el probervio que se suele dezir, por ventura uviera mirado muy bien y corregido la obra antes que la diera a estampar (Cicalamento XVI).

Io lascerò ora nel giudizio di chi conosce il pelo nell'uovo e che abbia pisciato in più nevi l'appiccare addosso a questo e a quell'altro (pág. 194).

Yo quiero dexar al juicio delos que se tienen por más sabios la aplicación (Cháchera última). 
A la cultura religiosa del traductor hay que añadir sus conocimientos de obras clásicas, buena muestra de lo cual es la cita de unos versos de Tibulo (Elegías, I, I, v. 33-34) que en el original, una carta dirigida a Doni que aparece en los Post Scripta, son incompletos y lacunosos, ya que no cumplen con su función, es decir, vehicular la idea sobre la que el autor de la carta quería insistir; en cambio, el traductor restituye la palabra clave latina ausente de la carta italiana (petenda) y además elimina la forma verbal al imperativo, poco oportuna e incluso ofensiva. Compárense el original (cuyo autor es un protonotario de nombre Pasqualigo) y la traducción, que presenta además ampliaciones para que se entienda bien la situación que las ha ocasionado y que por tanto facilitan la comprensión del pasaje:

Ma io, che son povero gentiluomo, mal posso donar cose degne di voi, però vi mando de' frutti del nostro orto e un salame che non è frutto dello orto, ma del porco, come sarebbe a dir in nostra lingua: zucca di carne salata pesta. Con questa scusetta appresso parcite, de magno est preda grege (pág. 387) ${ }^{14}$.

Pero yo, que soy un pobre cavallero, mal podré daros cosas conformes a vuestro valor; y por tanto os embío del fructo de mi huerto y una carga de salsijas o longaniças, las quales no son fruta de jardín, mas de puerco: como se podría dezir en nuestra lengua, una calabaça de carne salada menuda. Con esta escusacioncilla en compañía de mi presente, me perdonaréis, por que de magno est praeda petenda grege (Post scripta 15).

Su conocimiento del latín se deja entrever también en la crítica a las vulgarizaciones de clásicos latinos que constituye una parte sustancial de la dedicatoria y a la que luego volveremos. A todo eso hay que añadir un profundo conocimiento de la lengua italiana (y de su variante toscana) ${ }^{15}$ en la diversidad

${ }^{14}$ Esta carta apareció publicada en español antes que en italiano: su autor leyó la llamada "primera parte» de la Zucca, o sea las tres secciones que Doni tituló Cicalamenti, Baie, Chiachiere, y escribió esta misiva al autor para felicitarle, con tanta rapidez que se pudo insertar entre los Post scripta de la traducción; es una muestra más de los vínculos entre Doni y el anónimo traductor. En su versión original salió en la edición aumentada de la Zucca, que incluye Fiori, Foglie y Frutti della Zucca, y se imprimió entre 1551 y 1552 con el mismo editor.

${ }^{15}$ Compárese esta oración con la relativa traducción: «siete a Venezia e i traduttori vi piovono i quali hanno dato di naso insino a Fenestella» (pág. 218); «vos estáys en Venecia entre los impresores, y los intérpretes os llueven a cuestas, los quales han porfiado tanto en traduzir libros que han traduzido entre ellos a Fenestela» (Post scrita): la expansión ilumina el sentido del original que en su síntesis resulta oscuro, tanto que se le ha escapado incluso a la editora moderna del texto italiano; por otra parte, el verbo porfiar tiene una connotación irónica, en línea con la intención del original. Otra muestra del conocimiento del italiano por parte del traductor es la traducción de la locución coloquial hoy desusada «s'avea messo gli occhiali gialli» (pág. 173), que tampoco entiende la editora italiana, pero sí nuestro traductor, ya que añade a la traducción literal «se puso unos antojos amarillos» una ampliación clarificadora: «de suerte que pudieran dezir por él "Ojos ay que de lagaña se pagan”» (Cháchera III), como a querer decir que el personaje del que se habla ignoraba voluntariamente algunos aspectos de cierta situación. Su óptimo conocimiento del italiano no va en detrimento del español: la 
de registros que adopta el autor, entre los cuales el popular, al que pertenece la mayoría de los numerosos proverbios presentes en el texto, aspecto que sugiere que el traductor llevaba en Italia un buen número de años, en los que por otra parte no había olvidado su idioma de origen, ni la riqueza de su patrimonio paremiológico: tanto es así que a veces el traductor añade proverbios, poniendo dos donde Doni cita solo uno, como por ejemplo en los tres casos siguientes:

Già si soleva usare un proverbio, e s'usa ancora, il qual mostrerà che differenza è da uomo a uomo, o sia fuori o dentro nella città: Un uomo ne val cento e cento non vagliono uno (pág. 40).

Solíase usar un probervio, y aun agora creo que se usa, por el qual se conosçe la diferencia que ay de un hombre a otro, ora esté en su patria, ora fuera della:

Mucho va de Pedro a Pedro

O por otra manera:

Un hombre vale por ciento y ciento no valen por uno (Cicalamento $\mathrm{V}$ ).

Non si dovrebbe mai tentare le persone fuor di proposito perché si dice:

Chi cerca truova (pág. 115).

Ninguno devría tentar a otro fuera de propósito, por que dizen

El que busca halla.

Otro:

Topó con horma de su medida (Baia V).

Dopo l'aver riso un pezzo disse il conte Vespasiano: - Questa sarà buona da metter nelle vostre Baie perché c'è il proverbio prontissimo:

Ogni simile appetisce il suo simile - .

- Voi dite il vero, e si dice ancora:

Tal è, qual è - (pág. 123).

Después que reyeron un rato, dixo el Conde Vespasiano: - Este cuento será bueno para ponerle en vuestras Baias; aquí viene el probervio muy a propósito:

Ruyn con ruyn, que así casan en dueñas.

Y otro:

Tal para tal, Pedro para Juan-.

- Vos dezís verdad, por que también se dize:

Entre ruyn ganado no hay que escoger.

Y otro:

Qual más qual menos, toda la lana es pelos — (Baia X).

oración de Doni «l'aveva punto in un braccio» (pág. 128) se cambia en «le havía dado una estocada» (Baia XIII), con uso de un término apropiado en lugar del genérico del italiano. 
En cuanto a traducciones particularmente felices de dichos o proverbios, limitamos a unos pocos ejemplos la muestra, que dada la estructura de la obra - cada uno de los 29 cicalamentos, de las 24 baias y de las 16 chácheras contiene por lo menos un proverbio- podría ser mucho más amplia:

Tanto va la gatta al lardo, che la vi lascia la zampa (pág. 45).

Cantarillo que va muchas vezes ala fuente dexa la asa o quiebra la frente (Cicalamento VIII).

Ogni dritto ha il suo rovescio ${ }^{16}$ (pág. 51).

Donde las dan, allí las toman (Cicalamento XI).

Non cercar quel che non ti tocca (pág. 115).

No te metas en pleytos agenos (Baia V)

Garbuglio fa per i malestanti (pág. 118).

A río buelto, ganancia de pescadores (Baia VII).

Chi pratica col zoppo se gl'apicca (pág. 168).

Quien a ruin arbol se arrima, ruin sombra le cobija (Cháchera primera).

Gratugia con gratugia non fa cacio (pág. 169).

El asno y el buey jamás aran debaxo un jugo (Cháchera II).

Bisogna distendersi quanto è lungo il lenzuolo (pág. 172).

El Rey va donde puede y no donde quiere (Cháchera III).

Lo mismo se puede afirmar de otras expresiones pertenecientes a la fraseología, como la locución figurada presente en «me fue nesçesario tomar calças de Villadiego» (Cicalamento último), que traduce perfectamente la que emplea Doni, «nettare il paese» (pág. 88); o la oración «el Secretario, como leyó el soneto, arrebató a Juan Garrote y medióle con él las espaldas muy bien» (Baia XII), donde a los coloquialismos corresponden sendas formas coloquiales en el italiano: «Il secretario [...] gli spianó le costure mirabilmente e fece andare i battuti inanzi alla croce» (pág. 127).

Por tanto, aun aceptando que la traducción de la Zucca no obedeciese a inciativa propia sino a la del autor italiano o, como se nos indica, a la del conde de Martinengo, no parece acertado imaginar a nuestro traductor como una figura sumisa, dependiente de Doni o sin personalidad. Más bien es cierto lo contrario, ya que este hombre con ambición de escritor (como él mismo confiesa) se enfrenta al texto original con mucha inteligencia y capacidad traductora, demostrando su cultura y buena disposición para escribirir ${ }^{7}$. En la misma dedicatoria

${ }^{16}$ El proverbio español es más claro y explícito. Sobre el significado del italiano no hay duda, ya que interviene un segundo proverbio, citado justo después: «tal carne, tal coltello», traducido «a tal carne, tal cuchillo».

${ }_{17}$ Una de las muchas muestras del ingenio verbal del traductor queda manifiesta en las siguientes palabras, con las que presenta la obra al destinatario de la traducción: «[la Zucca] está llena de muchas y probechosas sentencias, de muy buenos exemplos, de sabrosos donaires, de apacibles chistes, de ingeniosas agudezas, de gustosas boverías, de graciosos descuidos, de bien entendidos motes, de dichos y prestezas bien dignas de ser sabidas, de manera que por ella se puede dezir "So el saial ay al". Lo que se vee paresçe cosa de burla y de lo que no se 
explica sus ideas sobre la traducción y aclara que no ha traducido «palabra por palabra» ${ }^{18}$, lo cual le permite la inserción de un largo excurso sobre las malas traducciones que se encuentran tanto del italiano al español — con el ejemplo de Boccaccio - como de las lenguas clásicas al español, y aquí, como anticipábamos más arriba, menciona las de Plutarco y Quinto Curcio, las cuales a menudo no tienen sentido, hasta el punto de causar un descrédito que afecta al autor original, según comenta en el mismo lugar de la dedicatoria; su polémica parece la de un traductor experto, que conoce las dificultades que esta tarea siempre lleva consigo y ve los defectos de las traducciones ajenas. Y la de la Zucca, pues, se propone evitar los errores que derivan de la literalidad y se plantea recrear el sentido del texto original. Con una figura ligada al imaginario religioso, el traductor explica: «la Zucca, en el vulgar Italiano, tiene tanta fuerza que a penas se puede traduzir en otra lengua con tanta [...]. Mi intención no ha sido, en la tradución deste libro, llegarme mucho ala letra, porque la letra mata, mas antes al espíritu, que da vida» ${ }^{19}$. Y con otra imagen, esta vez algo polémica e ideológicamente orientada, afirma: «es menester que en algunas partes tomemos el sentido y le bolvamos en otras palabras, y no queramos ir atados a la lettra como los Iudíos $»^{20}$.

A la luz de estas afirmaciones y a manera de conclusión provisional, parece posible proponer que este traductor anónimo sea un hombre culto, ortodoxo

paresçe todo, o la mayor parte, es de veras: es un reportorio de tiempos, una red varredera que todos los estados, oficios, edades recoge en sí; finalmente, es un Sileno de Alcibiades: a todos avisa, con todos habla, de suerte que asi grandes como pequeños, ricos y pobres, doctos y ignorantes, Señores y los que no lo son, viejos y moços, y en conclusión desde el Papa hasta el que no tiene capa, sin sacar ninguno, pueden sacar desta Zuca tanto çumo que salgan llenos, y la calabaça no quede menguada»; la mención del Sileno de Alcibiades puede ser una alusión erasmiana, aunque en otros lugares el traductor parece dar a entender que conoce los textos de Platón; obsérvese además el uso de proverbios, tan en línea con el texto de Doni.

18 Dice, por ejemplo, «cada lengua tiene sus particulares maneras de hablar, de manera que lo que suena bien en una bolviéndolo en otra, palabra por palabra, suena mal».

${ }_{19}$ Por otra parte la «fuerza» del texto original a la que alude el traductor es una referencia directa a Cicerón, que en De optimo genere oratorum (V 14) afirmaba: «non verbum pro verbo necesse habui reddere, sed genus omne verborum vimque servavi»; desde la Antigüedad la actividad traductora se ha valido de estas ideas directa e indirectamente y la preceptistica renacentista, recogiéndolas, hacía hincapié en la traducción no literal. Amplios panoramas diacrónicos y discusiones acerca de la traducción se pueden ver en C. Alvar, Traducciones y traductores. Materiales para una historia de la traducción en Castilla durante la Edad Media, Centro de Estudios Cervantinos, Alcalá de Henares, 2010, y en J. C. Santoyo, La traducción medieval en la Península Ibérica (siglos III-XV), Universidad de León, 2009.

20 Estos buenos propósitos, sin embargo, no siempre se cumplen y la traducción se conforma a veces con una literalidad que no comunica el sentido subyacente; este problema, en efecto, se manifiesta desde el título, que en italiano alude a la cabeza con la palabra zucca (o sea, «calabaza»), pero el traductor lo resuelve introduciendo con mucha habilidad el doble significado del italiano en la palabra española y eligiendo luego una u otra indiferentemente; para una explicación más detallada del proceder del traductor véase K. Baldinger, «La "Zucca del Doni” (Venezia, 1551) e la "Zucca del Doni en Spañol” (Venezia, 1551). Un confronto lessicale», en G. Holtus y M. Metzeltin (eds.), Linguistica e dialettologia veneta. Studi offerti a Manlio Cortelazzo dai colleghi stranieri, Narr, Tübingen, 1983, págs. 133-145. 
en cuestiones religiosas y buen conocedor de la doctrina y los textos sagrados: por otra parte, la primera etapa contrarreformista ya se había inaugurado y se estaba celebrando el Concilio de Trento. A parte de este aspecto ligado a la doctrina, se trataría de una figura en todo caso con amplios intereses culturales y cierta mundanidad, o por lo menos una voluntad y disposición al trato con personajes de la cultura y la buena sociedad de la época. 
